\title{
Esophagectomy in Scleroderma: Report of a Case
}

\author{
Erdal Yekeler ${ }^{\mathrm{a}}$ Nesrin Gürsan ${ }^{\mathrm{b}}$ \\ aDepartment of Thoracic Surgery, Region Training and Research Hospital, and \\ bepartment of Pathology, Atatürk University, School of Medicine, Erzurum, \\ Turkey
}

\section{Key Words}

Scleroderma $\cdot$ Stricture $\cdot$ Esophagectomy

\begin{abstract}
Scleroderma is a generalized autoimmune disease with variable involvement of the skin and major organs (esophagus, lung, heart and kidney). Scleroderma is essentially a skin disease that frequently involves the digestive system. In scleroderma, the esophagus is the most frequently affected organ of the digestive system, and esophageal dysmotility, reflux and stricture may be observed in the advanced stage. Balloon dilatation and bougienage are generally sufficient in patients developing stricture, and the number of cases in whom resection is performed is very low. In a 20-year-old patient with difficulty in taking even liquid foods, tests revealed sclerodermal involvement of the distal end of the esophagus and stricture. Esophageal resection and gastric replacement were performed. Such systemic diseases as scleroderma, although rare, must be considered in the differential diagnosis of nonmalignant dysphagia, and resection must be borne in mind as a surgical option in cases of advanced stricture.
\end{abstract}

\section{Introduction}

Systemic sclerosis or scleroderma is an autoimmune disease whose main clinical symptom is thickening and hardening of the skin. It may involve several vital organs (for example, the lung, heart, kidney, esophagus and intestine) and lead to progressive irreversible fibrosis in connective tissue [1-4]. Its etiology and pathogenesis are still largely unknown. The histological characteristic of the disease in the early stages is characterized by perivascular inflammation and endothelial call apoptosis, while in advanced cases it appears as excessive collagen accumulation in the skin and visceral organs [1]. It has two subgroups: diffuse systemic sclerosis, and limited disease with gastrointestinal manifestations possible in the subgroup. Clinically significant gastrointestinal involvement appears in around $50 \%$ of patients diagnosed with scleroderma in long-term follow-up [2]. This assumes the form of esophageal dysmotility, 
lower esophageal sphincter insufficiency, reflux, stricture, a reduction in motility in the intestine, wide-mouthed diverticles in the large intestine and rectal atonia in advanced cases [5]. The esophagus is the most frequently affected organ in the digestive system (7590\%) [3].

A review of the English language literature revealed very few cases with scleroderma causing stricture to such an extent that it created difficulties in taking liquid foods, and thus, gastric replacement was performed. This report presents a rare case of scleroderma, a type of skin disease that narrowed the esophagus to the extent of obstructing intake of liquid foods, and our surgical experience in the light of data from the literature.

\section{Case Report}

A 20-year-old male patient who had difficulty in swallowing solid foods for 2 years and liquid foods for the last four months was admitted to our clinic. On physical examination, cachexia, 'mouse-face' appearance, ulceration in the distal phalanges (fig. 1a) and metacarpo-phalangeal joint ulceration (fig. 1b) were identified. Almost full obstruction of the distal 1/3 of the esophagus and stricture were determined on barium images (ig. 2a). Esophageal endoscopy demonstrated hyperemia, fragility, edema and extreme narrowness at $29 \mathrm{~cm}$ obstructing the passage of the endoscope. In addition, localized ulcerated areas of mucosa were observed (fig. 2b). The endoscopic biopsy result indicated esophagitis. On thoracic CT, there was wall thickening in the distal part of the esophagus (fig. 2c). Apart from the skin test results, no findings of involvement of any other internal organ were determined. In serological analysis, Scl-70 and antinuclear antibody spotted form were positive. Skin biopsy results showed thinning in the epidermis and increased collagen-rich connective tissue in the dermis and around the subdermal sweat gland. All of these findings were compatible with scleroderma.

The patient was diagnosed as suffering from scleroderma. Therefore, the use of a proton pump inhibitor, D-penicillamine and nifedipine was started, and a balloon dilatation procedure was performed. The patient returned with increased complaints after 35 days. A second balloon dilatation procedure was performed, yet the complaints did not improve during follow-up. Consequently, surgery was planned.

Laparatomy, right thoracotomy with subtotal esophagectomy, proximal gastrectomy and esophagogastrostomy were performed, and a 12-cm segment was resected (fig. $3 \mathrm{a}$ ). During the dissection of the distal esophagus, advanced mediastinal adhesion and periesophageal mediastinal fibrosis were observed (fig. 3b).

In histopathological examination of the material (fig. 3b), microscopic investigation demonstrated fibrous thickening of the esophageal wall, particularly the submucosa, with atrophy of the muscularis propria; atrophy and fragmentation of the smooth muscle began in a patchy distribution to a greater extent in the circular rather than the longitudinal muscle layer. There was diffuse collagen infiltration and fibrosis and the number of gap junctions located between the smooth muscle cells had decreased, resulting in fibrosis and thickening of the serosal layer. There was a pathological change in the vasculature, especially in the small arteries. The intima was enlarged concentrically with proliferation, and the endothelial cells were swollen. The adventitia had developed a fibrotic cuff around the artery, which might have obliterated the periarterial capillaries and lymphatics. In the histopathological analysis, these findings were reported as sclerodermal involvement of the esophagus. No pathological changes within surgical limits were determined.

The patient was discharged without complications on postoperative day 12 . He was started on $900 \mathrm{mg} /$ day D-penicillamine and $20 \mathrm{mg}$ /day nifedipine preoperatively and discharged with the same treatment. No recurrence was observed for two years of follow-up and in periodic check-ups with endoscopy and barium imaging.

\section{Discussion}

The main symptom of scleroderma appears in the skin, and it is regarded as a skin disease. It may be seen at any age, though more often in middle age. It is more frequent in 
women. The commonest initial manifestation of the disease is Raynaud's phenomenon. In the advanced stage of the disease, lung, kidney and heart involvement may lead to death $[1,2,6]$. Gastrointestinal system involvement is frequently observed. Esophageal involvement in adults accounts for nearly $75-90 \%$ of cases. The distal $2 / 3$ of the esophagus is frequently affected $[3,5]$.

In scleroderma, motility impairment appears as the result of damage arising in the esophageal wall and collagen tissue. The true pathology is muscle fibre atrophy, collagen accumulation in connective tissue, and subintimal arterial fibrosis. Arteriole changes in the vasa nervorum and collagen accumulation-related neural dysfunction occur. Although the picture appears myogenic, it follows a course with degeneration in Auerbach's plexus. Esophageal emptying is delayed due to ineffective peristaltic movements; lower esophageal sphincter pressure falls and gastroesophageal reflux develops [7]. Related to this, candida esophagitis, erosive esophagitis, Barrett's esophagus, diverticles, fibrous stricture, and malignancy may develop as complications.

Macroscopically, findings particular to a widened esophagus are determined. The radiological finding is esophageal atonia. Stricture and findings compatible with esophagitis may be determined in endoscopic examination. Manometrically, low-amplitude peristaltic contractions and a reduction in lower sphincter pressure are typical $[6,7]$. Pyrosis, dysphagia, acid regurgitation, aspiration, chest pain, nausea, and vomiting are complications frequently encountered with esophageal involvement of scleroderma. Difficulty in swallowing is the cardinal symptom in patients developing stricture [5-7].

The basic pathogenesis in esophageal involvement of scleroderma is reflux, and the development of esophagitis is inevitable in long-term untreated reflux. Therefore, the basic principle for esophageal involvement of scleroderma is medical treatment to prevent reflux esophagitis. In addition to conservative measures such as diet, eating little amounts but often and lying with the head elevated, antacid drugs, prokinetic agents and mucous protecting drugs are available. In cases in whom no results are obtained with medical treatment, antireflux surgery is an option. Antireflux operations are known to relieve the symptoms but not to provide a total cure $[3,7,8]$.

The long-term complication in untreated reflux and esophagitis is stricture. Peptic strictures are the most frequently seen benign strictures of the esophagus. However, the realization that reflux is the main element in the mechanism by which stricture arises and the use of proton pump inhibitors and $\mathrm{H}_{2}$ receptor blockers has recently lowered the level of peptic stricture [9]. In addition to peptic stricture, trauma (spontaneous rupture, foreign body, iatrogenic), corrosive ingestion, postirradiation, inflammatory, webs (Plummer-Vinson, Schatki's ring, keratotic) and collagen tissue diseases may be included in the etiology of acquired esophagus stricture [10]. The first treatment principle of choice in stricture is balloon dilatation and bougienage. In young patients in particular, it is more difficult to dilate the strictures, and there is a need for frequent dilatation [9]. Resection must be considered in cases of untreatable recurrent stricture. In addition to recurrent stricture, resection indications in esophageal strictures may be undilatable strictures, strictures with a risk of perforation if dilated, increased stricture dilatation frequency, serious dysplasia and suspicion of malignancy [10]. If surgical resection is required, the stomach, jejunum and colon may be used as replacement organs. It should also be kept in mind that the jejunum and colon may be involved in scleroderma as well [11].

Drug therapy must be added to surgical treatment of stricture in order to prevent recurrence. The treatment of scleroderma has evolved considerably. Specific treatment 


\begin{tabular}{r|l|l|l} 
Case Reports $/ \mathrm{h}$ & $\begin{array}{l}\text { Case Rep Gastroenterol 2008;2:499-504 } \\
\text { D0I: 10.1159/000161565 }\end{array}$ & Published online: December 5, 2008 & $\begin{array}{l}\text { O 2008 S. Karger AG, Basel } \\
\text { ISSN 1662-0631 } \\
\text { www.karger.com/crg }\end{array}$ \\
\hline
\end{tabular}

using immunomodulators have provided good outcome. D-penicillamine is the agent from which the most satisfactory results have been obtained. Nifedipine should be added to treatment in patients with Raynaud's phenomenon $[4,12]$.

Systemic diseases such as scleroderma must be borne in mind when examining the etiology of nonmalignant dysphagia of the esophagus. In cases developing advanced and undilatable stricture, as did our patient, esophagectomy may be the best treatment option.

Fig. 1. The patient's distal phalanges (a) and ulceration in the metacarpo-phalangeal joints (b).
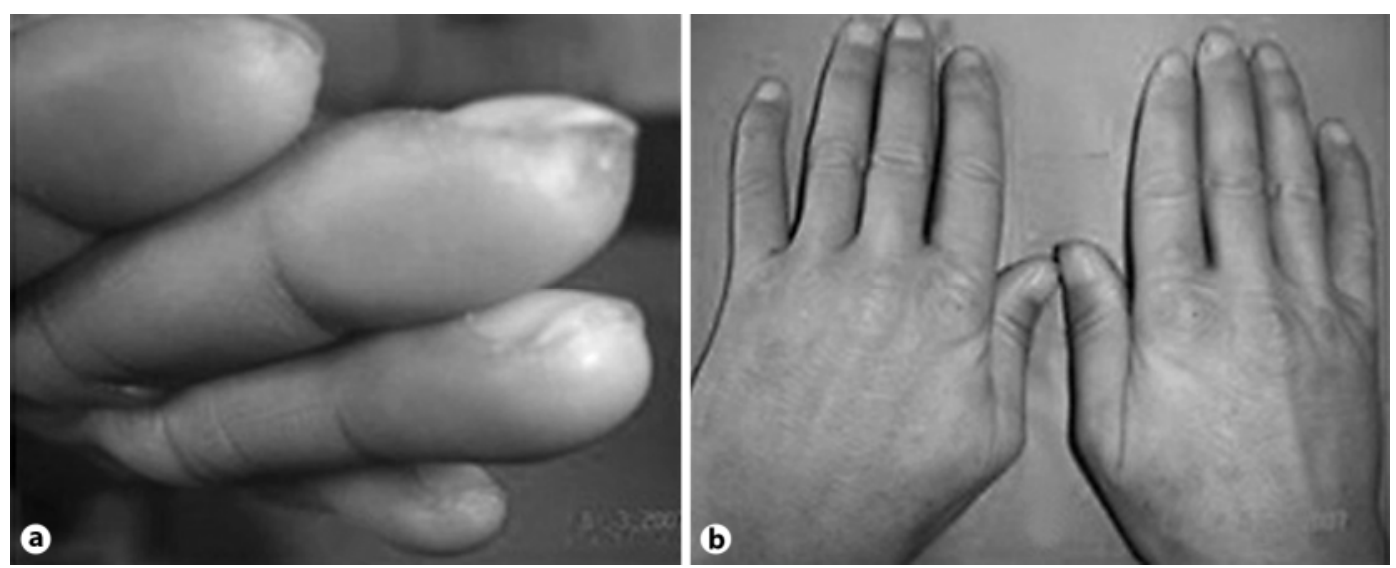

Fig. 2. Almost total obstruction in $1 / 3$ of the distal section on barium images of the esophagus (a), mucosal ulcerations and advanced narrowing of the lumen in endoscopic evaluation (b) and esophageal wall thickening giving a mass impression on thoracic CT image (c).
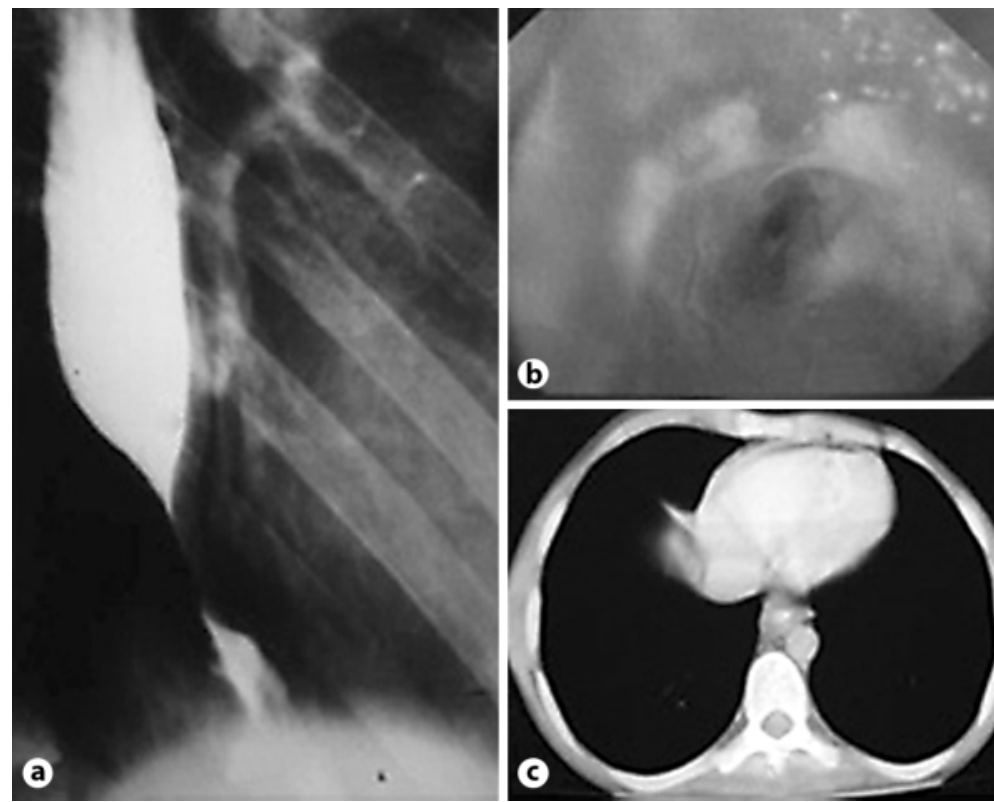


\begin{tabular}{r|l|l|l} 
Case Reports $/ \mathrm{h}$ & $\begin{array}{l}\text { Case Rep Gastroenterol 2008;2:499-504 } \\
\text { D0I: 10.1159/000161565 }\end{array}$ & Published online: December 5, 2008 & $\begin{array}{l}\text { O 2008 S. Karger AG, Basel } \\
\text { ISSN 1662-0631 } \\
\text { www.karger.com/crg }\end{array}$ \\
\hline
\end{tabular}

Fig. 3. a The surgical material removed. b The picture of the distal esophagus of our patient with scleroderma showing the tendency of smooth muscle bundles to have central atrophy (Masson trichrome staining, $\times 200)$.
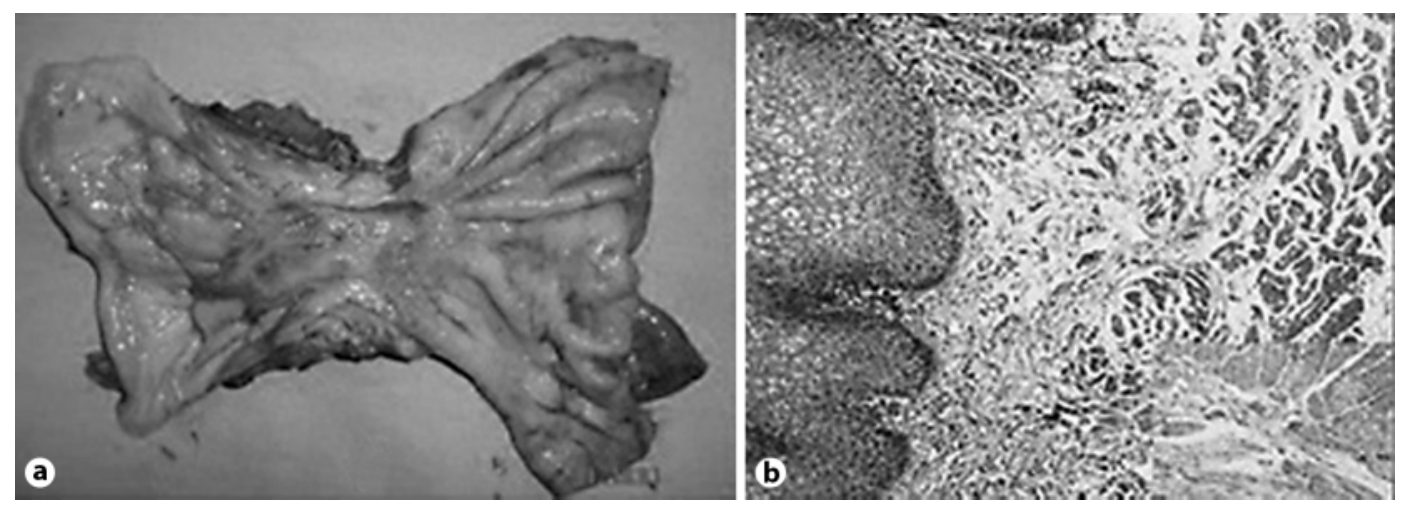


\section{References}

1 Kahari VM: Activation of dermal connective tissue in scleroderma. Ann Med 1993;25:511-518.

2 Hostein J, Fournet J: Gastrointestinal manifestations of collagen diseases. Dig Dis $1986 ; 4: 240-252$

-3 Sjogren RW: Gastrointestinal motility disorders in scleroderma. Arthritis Rheum 1994;37:1265-1282.

4 Connolly MK: Scleroderma. Dermatol Ther 2001;14:81-94.

5 Bassotti G, Battaglia E, Debernardi V, et al: Esophageal dysfunction in scleroderma. Arthritis Rheum 1997;40:2252-2259.

-6 Steen VD, Medsger TA Jr: Severe organ involvement in systemic sclerosis with diffuse scleroderma. Arthritis Rheum 2000;11:2437-2444.

7 Henry MA, Harbermann MC, Rocha OM: Esophageal motor disturbances in progressive systemic sclerosis. Dis Esophagus 1999;12:51-53.

8 Poirier NC, Taillefer R, Topart P, Duranceau A: Antireflux operations in patients with scleroderma. Ann Thorac Surg 1994;58:66-73.

9 Richter JE: Peptic strictures of the esophagus. Gastroenterol Clin North Am 1999;28:875-891.

10 Jeyasingham KJ: Benign strictures of the esophagus; in Shields TW, Lo Cicero J III, Ponn RB (eds): General Thoracic Surgery. Philadelphia, Lippincott Williams \& Wilkins, 2000, pp 1865-1880.

11 Mansour KA, Malone CE: Surgery for scleroderma of the esophagus: a 12-year experience. Ann Thorac Surg 1988;46:513-514.

12 Stummvoll GH: Current treatment options in systemic sclerosis (scleroderma). Acta Med Austriaca 2002;29:14-19. 